\title{
Post-blast slope stability monitoring with slope stability radar
}

\author{
P Saunders GroundProbe Pty Ltd, Australia \\ JM Kabuya ArcelorMittal Mining Canada, Canada
}

A Torres GroundProbe, USA

R Simon École Polytechnique de Montréal, Canada

\begin{abstract}
It is generally understood that the quality of a rock mass in an open pit mine may be subject to progressive deterioration over time as a direct result of vibration, due to successive blasting and other mining activity. This paper defines a process for quantifying this damage using historic slope stability radar (SSR) data using assumptions based loosely on the model as described by Mercer \& Stacey (2008). A method for monitoring in real time is also presented with the aim being to provide early warning of significant damage caused by production blasting. A case study is presented based on analysis conducted at ArcelorMittal's Mont-Wright mine in Quebec where historic SSR data was collected between October 2011 and December 2012. The data was reprocessed, analysed and interpreted to assess for signs of significant historical damage caused as a direct result of production blasting. The aim of this project was to provide information and input for the mine to assist with production optimisation of future blast design, machinery selection, and to assist with forecasting associated production rates and maximising project profitability.
\end{abstract}

Keywords: open pit, slope stability monitoring, slope stability radar, post-blast damage

\section{Introduction}

The Mont-Wright mine, operated by ArcelorMittal Mining Canada, is in northeastern Quebec, near the town of Fermont, Quebec (Figure 1).

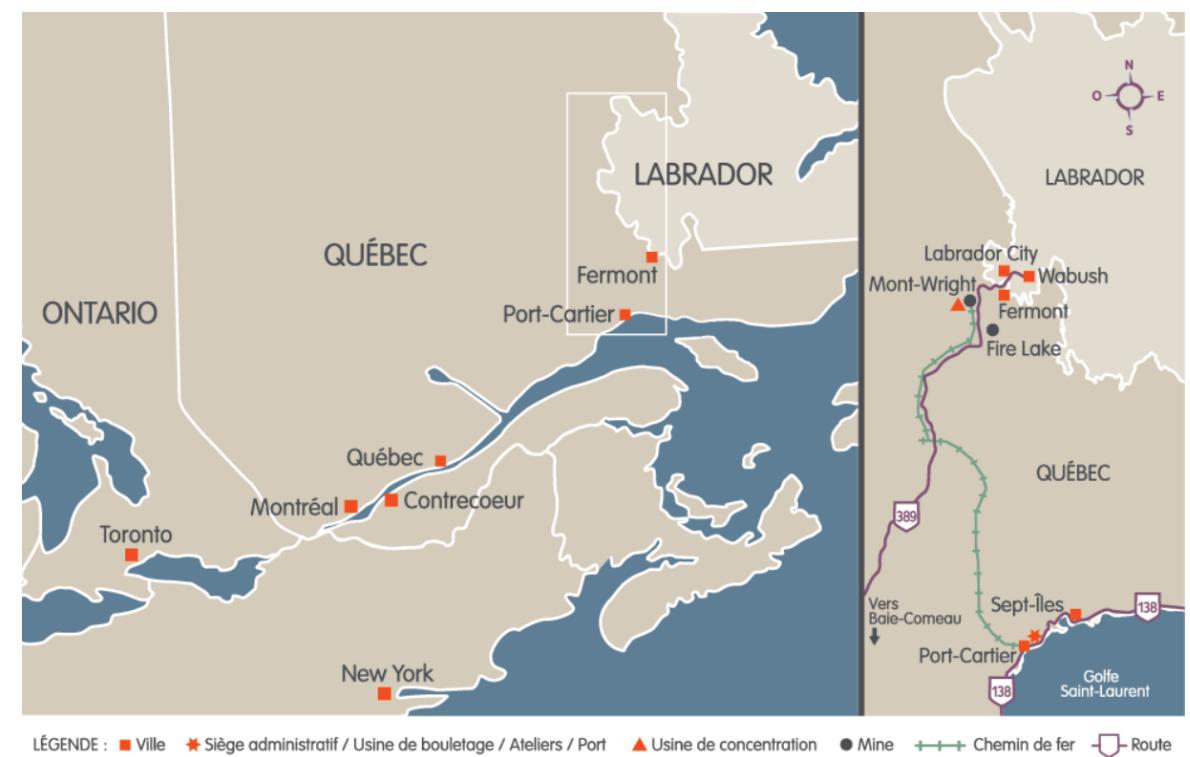

Figure 1 Mont-Wright site localisation (Kabuya 2019)

The mine opened in the early 1970 s and is comprised of several open pits, with the oldest and largest active open pit being Paul's Peak. In 1998, an external geotechnical consultant conducted a slope design study of the Paul's Peak area, producing slope design criteria for the proposed ultimate pit. Since 1998, the 
geotechnical consultant has undertaken geotechnical site inspections and assessments of the southeast wall on an annual basis. In 2007, when the slope had reached a height of 200 to $270 \mathrm{~m}$, it was recommended to ArcelorMittal Mining Canada to use slope stability radar (Noon 2003) at Paul's Peak, given the potential negative impact of slope failure on the continued safe operation of the mine. In 2009, the geotechnical consultant proposed a large-scale pushback of the Paul's Peak south pit wall for safe mining to recommence at the bottom of the pit in front of a large slope failure that occurred in 1986/1987 (P1 area). This plan was called the 'Offload' project and it started in 2011 but was suspended in 2012.

It is generally understood that the quality of a rock mass will progressively deteriorate as a direct result of vibration, due to successive blasting and other mining activity over time. So, prior to recommencement of mining of the Offload in 2017, the study as described in this paper was carried out by GroundProbe to attempt to evaluate the long-term impact of blasting activity on slope stability during the period October 2011 to December 2012. The principal aim of this project was to provide information and input for the mine to assist with production optimisation of future blast design, machinery selection, and to assist with forecasting associated production rates and maximising project profitability. For that purpose, long-term and post-blast deformation analyses were conducted in order to attempt to identify evidence of rock mass damage or deterioration, either on a regional or local scale, during that period. Based on the results of the long-term deformation and post-blast damage assessments, an economic benefits assessment of post-blast slope stability monitoring with slope stability radar (SSR) was carried out. To quantify the cost benefits from the study, the maximum tonnage per blast was evaluated against previous mining practices. The cost to production of post-blast waiting time for resumption of mining activities was also compared, considering real-time SSR data analysis for risk management versus a standard re-entry time of 20 hours.

\section{Site description}

\subsection{Regional geology}

The Mont-Wright orebody is located in the Severson Range, in the southwestern portion of the QuébecLabrador Trough (QLT). These rocks belong to the Kaniapiskau Group, a succession of regionally metamorphosed clastic and chemical sediments unconformably overlying basement gneisses of the Archaean Ashuanipi Complex. The Kaniapiskau Group consist of former greywackes, limestones, sandstones and ferruginous sediments that have been metamorphosed to mica schists, marbles, quartzites and coarsely crystalline Iron Formation (Hagegeorge et al. 1971). The QLT sedimentary belt is 1,200 km in length, with a sinuous to arcuate surface expression and is of Huronian age (2.48 to $2.22 \mathrm{Gya}$ ). These sediments were deposited in a geosynclinal structural depression on top of Archean gneisses. The QLT sediments are divisible into three regions based on the metamorphic grade of the constituent rocks. The sediments in the southwestern area of the geosyncline, in which Mont-Wright is located, were subjected to intense folding and metamorphism (Bourassa 1977).

\subsection{Lithology}

There are four primary rock lithological units in the south wall of the Paul's Peak: Iron Formation (IF), Quartz Rock Mica Schist (QRMS), Quartzite (QR) and Amphibolite (AMP). The lithological units are described as follows:

- The ore occurs in iron rich units of the Sokkoman Formation. This unit is described as a mediumgrained, well banded, homogenous grey to pale blue rock, comprised mainly of hematite and quartz, with minor amounts of magnetite. The IF unit also contains a number of smaller continuous and discontinuous bands of QRMS, AMP and QR.

- Weathering of the iron formation results in a heavily oxidised and leached condition, producing a very friable texture which can occur to significant depths (approximately one $\mathrm{km}$ ). Weathering primarily occurs along fracture zones and formational contacts. The rock in these zones can be badly 
disintegrated, composed of friable, coarse, granular, quartz, limonite, goethite and minor manganese, with a sugary texture.

- The IF is underlain by, and locally interbedded with, the Wishart Formation, a sequence comprised of slightly to moderately foliated quartzite (QR), and more strongly foliated quartz mica and mica schists (QRMS). The two units, QR and QRMS, are classified according to mica content. Gradational contacts frequently exist between these units and with the overlying IF. The schistosity within the QRMS is typically well developed, and where the mica contents are high (i.e. $>40 \%$ ) the rock tends to be very fissile.

- The AMP units are often found intruding, and interbedded with, both the IF and QRMS rock. It is typically described as a medium-grained rock comprised of greenish amphibolite, feldspar, biotite, and garnet. Locally, the AMP has been subject to argillic alteration, forming a soft (average thickness one metre) plastic clay, particularly along contact zones. The argillic alteration is not restricted to contact with the IF; AMP can show signs of alterations along contacts with QR or QRMS.

\subsection{Structural geology}

Large-scale structures in the Mont-Wright area consist of two major sets of north-plunging isoclinal folds. These structures are generally tightly folded along east and northeast trending axes, with more open and broadly folded limbs along northwest trending axes. The Paul's Peak orebody is located within the synclinal section of these large structures. The anticlinal structures appear generally symmetrical; however, isoclinal folding of the iron formation in the synclines appears to have created a more distorted structure, exhibiting flow and associated parasitic folding, resulting in localised thickening of the iron formation. A second phase of deformation has superimposed folding that creates an irregular structure as a result of warping of axial planes of the earlier folds. This is apparent in Paul's Peak area. The end result of the folding is the creation of fold limbs that generally dip $40-50^{\circ}$ to the west and northwest, but with local variations, including overturned sections in the footwall area of Paul's Peak and flattening in the hinge areas of the major folds.

Concerning smaller-scale structures, three main sets of cross-joints are apparent. One set which is parallel to the bedding, one set that strikes approximately perpendicular to the bedding and dips steeply to sub-vertical, and a set that strikes essentially parallel to bedding and dips approximately normal to bedding. An additional one or two weakly-developed joint sets, which occasionally form a conjugate set, appear to occur locally.

\section{$2.4 \quad$ Slope geometry}

A major slope failure that occurred in 1986/1987 on the south wall of Paul's Peak can be seen in Figure 2. The scan area and the radar location remained relatively consistent during the monitoring period. This allowed reasonably easy identification of common features and selection of appropriate control points in all the wall folders that were analysed for continuity.

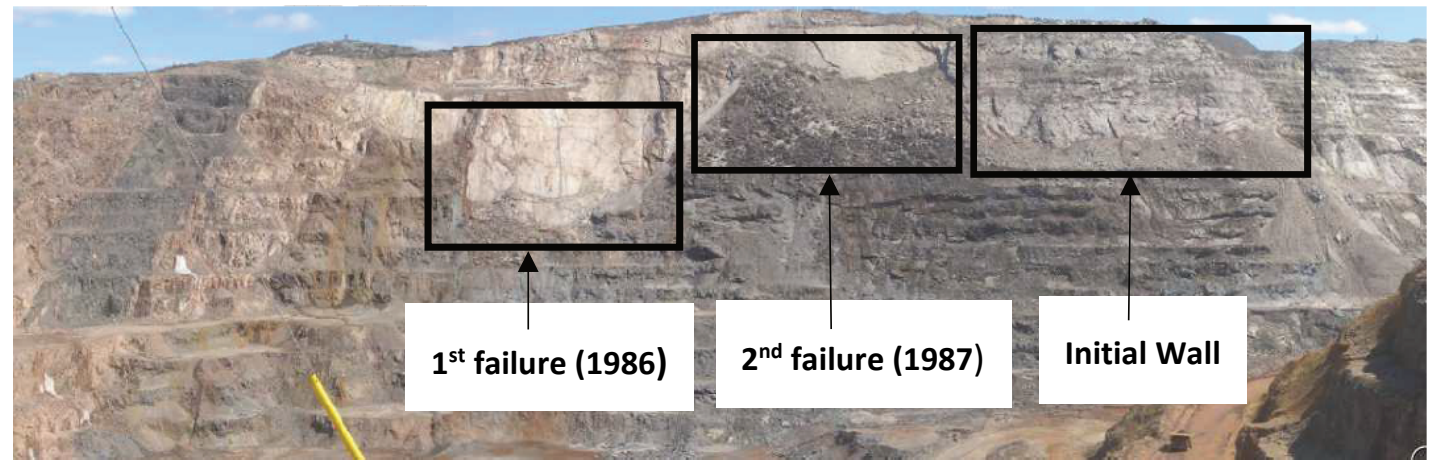

Figure 2 Southeast wall of Paul's Peak

The 1986/1987 failure area is largely located above the 678 elevation step-out, within schistose rocks. Below 678 elevation, the rock mass consists largely of Iron Formation. While the upper slope has been developed 
un-benched and failed along continuous structures parallel to the bedding (JS1), presplitting has been used in the iron formation rocks to develop a benched slope with safety berms. Although JS1 discontinuities have been undercut by the presplitting and bench crests have generally broken back along what appear to be JS1 structures, it would also appear that remnants of the safety berms have been retained in some areas. This would indicate that the JS1 structures are less continuous in the iron formation than in the schistose rocks. Concerning the pushback wall, it was recommended that bench faces be mined parallel to the strike of the prominent JS1 discontinuity set. Consequently, bench face angles were developed dependent on the local dip of the JS1 set (which is interpreted to range between 40 and $55^{\circ}$ ). Where the trend of the slope is slightly oblique to the strike of JS1 set of structures $\left(>20\right.$ to $\left.30^{\circ}\right)$, it was recommended to develop a benched presplit slope with bench faces mined at $70^{\circ}$. A bench height of $28 \mathrm{~m}$ and berm width of $14 \mathrm{~m}$ were recommended because slope aspect is considered to be outside of the planar sliding envelope. Based on the recommended bench face angles, bench heights and berm widths, resultant inter-ramp slope angle was less than $50^{\circ}$ to not undercut structure on large-scale.

\subsection{Blast design history}

A total of 58 blasts were registered at Offload between October 2011 and December 2012. The blast design during this period consisted of $165.1 \mathrm{~m}$ diameter holes with a depth of $7 \mathrm{~m}, 250-300 \mathrm{~kg}$ as maximum allowable charge weights per delay. A total of 163 valid seismic records were compiled during blasting. A damping law specific to the sector studied was developed at a $95 \%$ confidence level. It is given by the following equation (Andrieux 2016):

$$
\mathrm{PPV}_{95}=734\left(\mathrm{~d} / \mathrm{W}^{0.5}\right)^{-1.32}
$$

where:

$$
\begin{aligned}
& \mathrm{PPV}_{95}=\text { peak particle velocity at a } 95 \% \text { confidence level }(\mathrm{mm} / \mathrm{s}) . \\
& \mathrm{d}=\text { distance from blasting to point of interest }(\mathrm{m}) . \\
& \mathrm{W}=\text { maximum explosive charge }\left(\mathrm{m} / \mathrm{kg}^{0.5}\right) .
\end{aligned}
$$

The amplitude constant is 734 and the attenuation constant is -1.32 .

This damping law must be continuously updated with seismic data acquired during future blasting.

\section{Methodology}

The aim of this study was to evaluate the long-term impact on slope stability due to blasting/mining activity during the period October 2011 to December 2012, prior to recommencement of mining a major cutback at Mont-Wright Mine. The project included both a regional and local scale assessment of response to blasting, mining and environmental conditions.

The deformation data that was collected by the SSR systems during the period October 2011 to December 2012 was collected, processed and analysed in order to: a) evaluate the long-term regional deformation processes at a number of suitable control points on the rock mass; b) evaluate the local response of the rock mass to each of the individual blasts during the monitoring period; and c) assess the data for significant long-term deformation trends.

The information collected by the SSR systems constitutes a total of 4,913 hours of monitoring data. It should be noted that the total monitoring hours corresponds to only $46 \%$ of the full-time period from October 2011 to December 2012 due to gaps in monitoring during some periods. This is represented in the long-term deformation plots as gaps in the deformation data. 


\subsection{Data acquisition and quality assessment}

The information required for the analysis was collected and provided by the Mont-Wright Geotechnical department. A detailed data quality assessment was completed for each of the wall folders to assess the performance of the system, the scan area configuration and the overall quality of the deformation dataset.

The objective of this stage was to identify and improve, where possible, data that had been affected by sub-optimal system settings, irregularities in the scan area configuration, or rapid atmospheric events and subsequent deformation correction.

\subsection{Regional versus local response to blasting}

When considering the potential impact of mining activity and blasting on the stability of the overall slope, the initial stage of this study involved selection of representative control points for the entire scan area. This was considered an important initial stage to demonstrate whether blasting had any regional scale impact on the slope.

There are two key mechanisms that take place to destabilise the rock mass when blasting near geological structures; gases can be pushed into the open fractures effectively 'activating' them causing displacement on a slope scale. Thus, even very small, displacement on slope-scale structures leads to compensatory displacement on smaller associated joint planes within the rock mass caused by stress redistribution (en échelon or subparallel joint sets). This can lead to extension of existing fractures and initiation of new fractures within the rock mass effectively decreasing internal shear strength. On a regional scale, it is assumed that very small displacement on large continuous structures can have a significant impact on the surrounding rock mass, effectively decreasing the inherent strength and stiffness of the overall slope, eventually leading to collapse. Evidence of the impact of this disturbance can be detected by identifying slow, slope-scale deformation processes over extended periods that occur at rates higher than the background deformation rate.

The other visible impact of blasting on the rock mass is the immediate local deformation response, in the wall behind or in front of the blast itself. This response is caused by the local energy transfer into the rock mass causing a 'shock' effect and is best minimised by applying effective blasting techniques such as trim shots, free-facing shots etc., to reduce the amount of energy transferred into the surrounding rock. An immediate spike in measured deformation is generally observed followed by a clear, regressive deformation trend (decelerating) over some period after the blast. Where the rock mass is particularly stiff, this regressive deformation trend may not be seen or noticed, depending on the sensor/radar sample rate (scan time). Stiff systems will tend to show a less pronounced regressive trend (if at all) than soft systems (weak material) with a lower modulus. When considering the significance of the time-to-stable metric and/or the post-blast velocity of the local slope, one should take into consideration whether the rock mass is considered to be a 'stiff' or a 'soft' system. For example, a long-observed time-to-stable period for a stiff system will be more significant with regard to rock mass damage than when observed for a low modulus soft system. Regional scale internal stiffness of a rock mass can be difficult to quantify. It is generally related to the persistence of structural features and larger scale internal fabrics rather than those that influence corescale modulus test results in a laboratory. Hence the scale effect must of course be taken into consideration.

For this study, the actual location of each blast was not provided and so the location was determined by observing the deformation and coherence data collected by the SSR immediately after the registered blast times. Using coherence, it was possible to precisely identify the region on the slope behind that had been impacted by the blast. A large spike in deformation was also generally observed. This area was then selected as the local control point for analysis of that individual blast.

\subsection{Radar data reprocessing}

The SSR wall folder reprocessing procedure allows analysis of the raw deformation information as it was measured by the SSR systems before applying the atmospheric correction. This process is conducted for those 
wall folders where either the stable reference area configuration or the atmospheric correction algorithm performance was sub-optimal. Newly optimised stable reference areas are selected based on the analysis of both the original and other wall folders and deformation is recalculated manually using Matlab code, scan-by-scan, with this improved configuration for atmospheric correction.

The reprocessing significantly reduced the noise floor in the deformation data and allowed for analysis of deformation trends that may not have been easily identifiable in the original dataset.

\section{$4 \quad$ Results}

\subsection{Long-term deformation assessment}

From the available data, there was no clear evidence of progressive blast damage, either at a regional or local scale. No increasing trend in the length of time-to-stable or post-blast velocity was observed at any of the control points.

Control points 5, 8, 9 and 10 showed the largest cumulative deformation magnitude. Although this does not necessarily suggest progressive damage to the rock mass at those points it was recommended to monitor the behaviour and assess ground conditions at these locations during mining.

Mercer's time and event dependent rock mass deformation model (Mercer \& Stacey 2008) was considered a guide to demonstrate the potential progressive deterioration of the rock mass as a result of successive blasting or other triggering events over an extended period. An increasing trend in the length of time-to-stable or observed post-blast velocity may suggest cumulative damage has occurred and that the area has progressed from elastic to plastic type deformation, approaching its yield point (Figure 3 ).

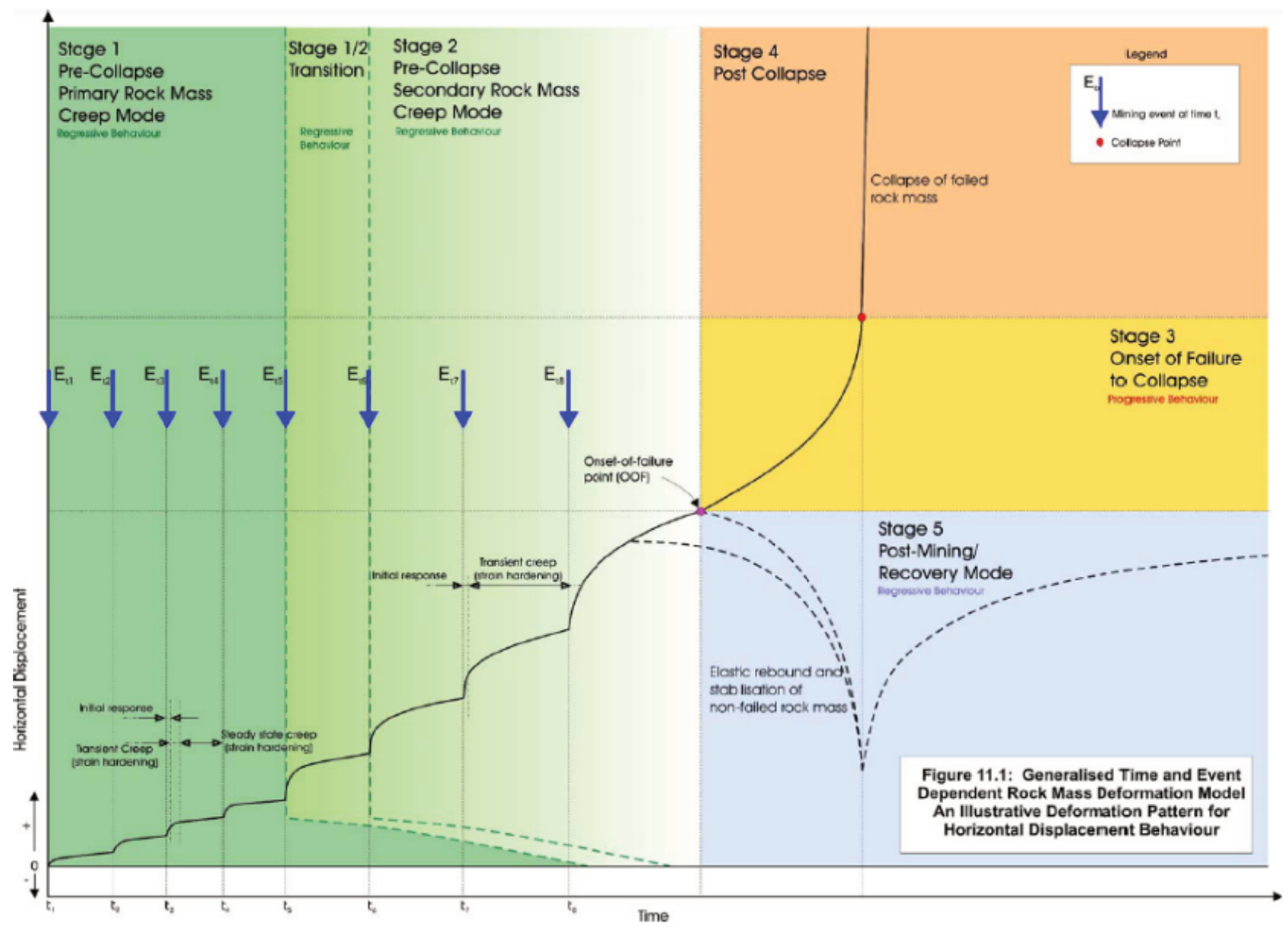

Figure 3 Time and mine event dependent rock mass deformation model (Mercer \& Stacey 2008) 
This method has been applied successfully in the past by the author with real SSR deformation data used to create long-term deformation plots that show evidence of rock mass damage due to triggering events (blasting). An example of one such case study is presented herein. This dataset shows blast events with an increasing transient creep (strain hardening) stage (regression deformation trend) following subsequent blasting. It can also be seen that the velocity of the slope progressively increased after each blast, leading finally to the onset of failure (OOF) point and the Stage 3 onset of failure to collapse. In this case study, a three-month deformation plot was created using the same process that was applied for the Mont-Wright study. These observations allowed site to proactively identifying a forthcoming slope-scale collapse and to put in place appropriate control measures, including a critical monitoring strategy and review of site processes for radar monitoring in the area.

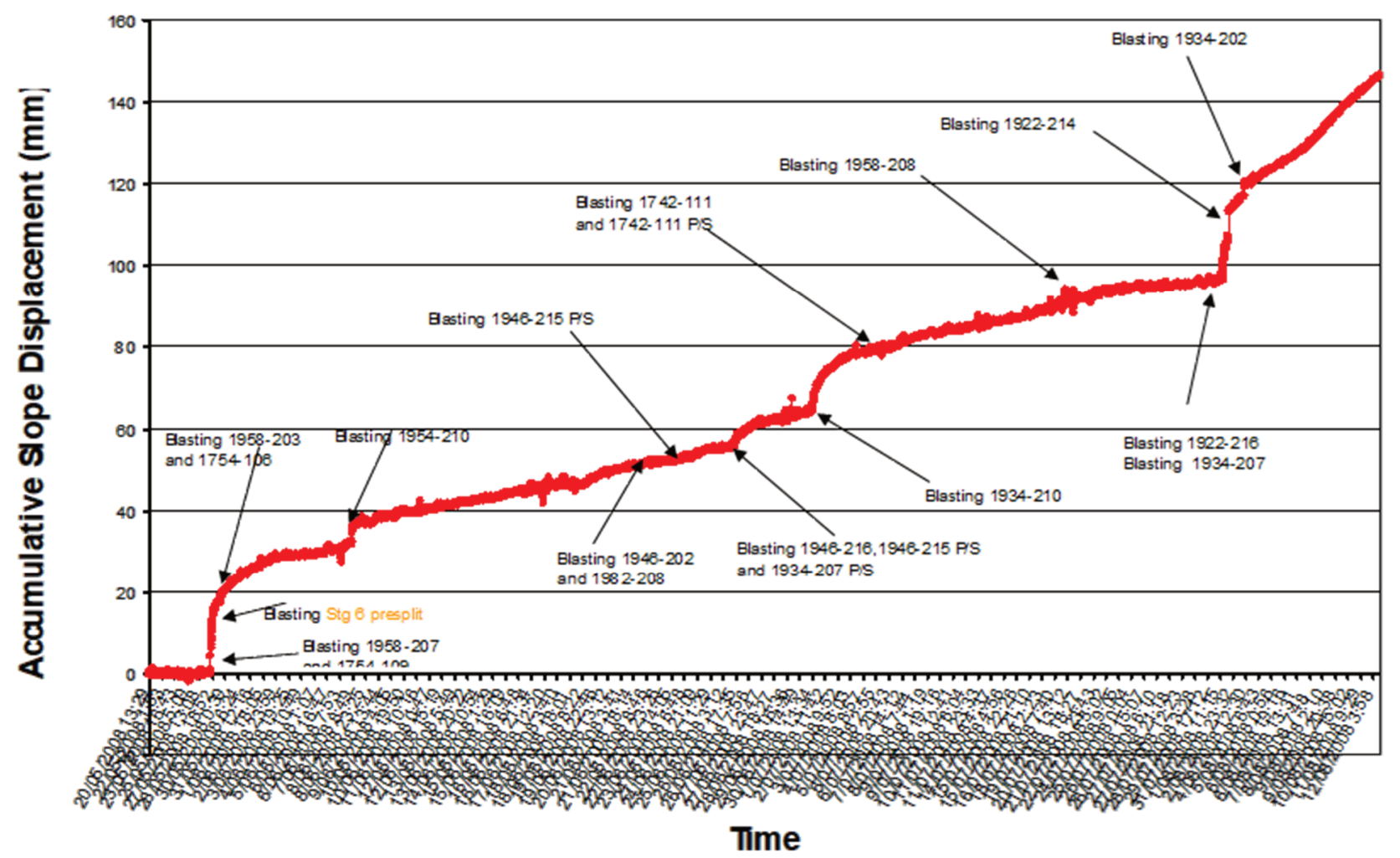

Figure 4 Three-month post-blast analysis plot from previous case study

For the Mont-Wright analysis, the following tasks were performed in order to build the long-term deformation plots:

1. The data quality was assessed, and the wall folder was reprocessed (where necessary).

2. A precise camera alignment was undertaken on each wall folder in order to ensure the consistency in the location of the control point that would be used during the process.

3. Manual fixes were applied in order to remove anomalous negative and positive spikes in the deformation plots which were correlated either with atmospheric events or SSR movement. This procedure was not used to force consistent deformation plots, only to remove data that was considered corrupted.

4. A search for consistent and coherent areas on the rock mass was performed by using the SSR information (deformation and coherence images, photographs and weather registers). Only areas with high coherence were considered suitable for stable reference area (SRA) locations and control points. Areas where either loose material or snow had accumulated were not used.

5. Eleven control points were selected. These locations and their naming convention were kept consistent for the period of analysis (October 2011 to December 2012). 
6. After the figures were recreated in the new reprocessed wall folder, a search for new, previously unidentified areas showing significant deformation trends was undertaken.

7. Finally, data 'stitching' was completed in order to determine the overall trend of the deformation plots over the full-time period.

\subsection{Post-blast damage assessment}

Figure 5 shows the control points (Figure 0 to 10) that were defined for the long-term deformation analysis for Mont-Wright mine. As stated previously, only consistent and coherent areas were chosen for analysis.

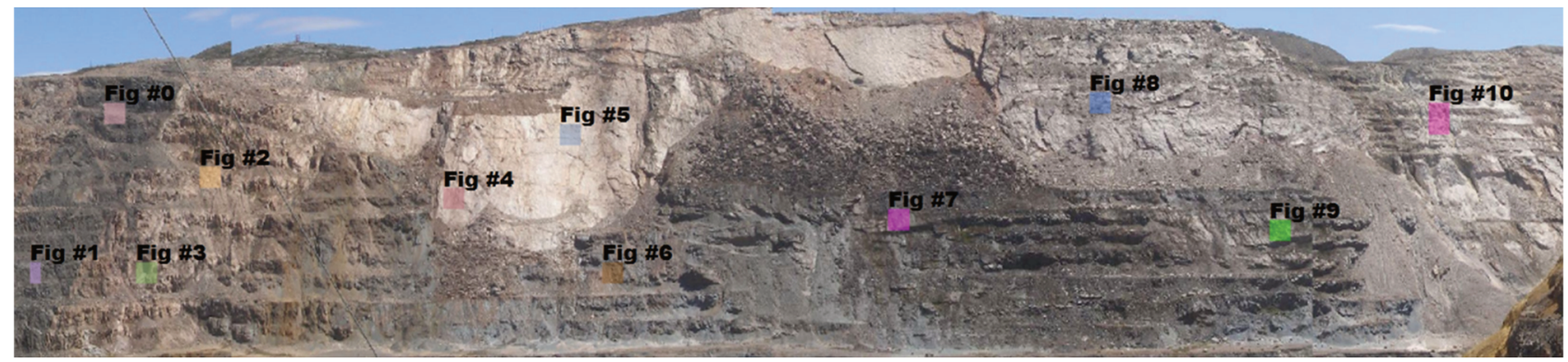

Figure 5 Selected control points for long-term post-blast analysis at Mont-Wright mine

Figure 6 shows the long-term accumulated deformation plots for the selected control points for the complete dataset over the period 16 October 2011 to 31 December 2012. These trends represent the regional response to mining activity during this period.

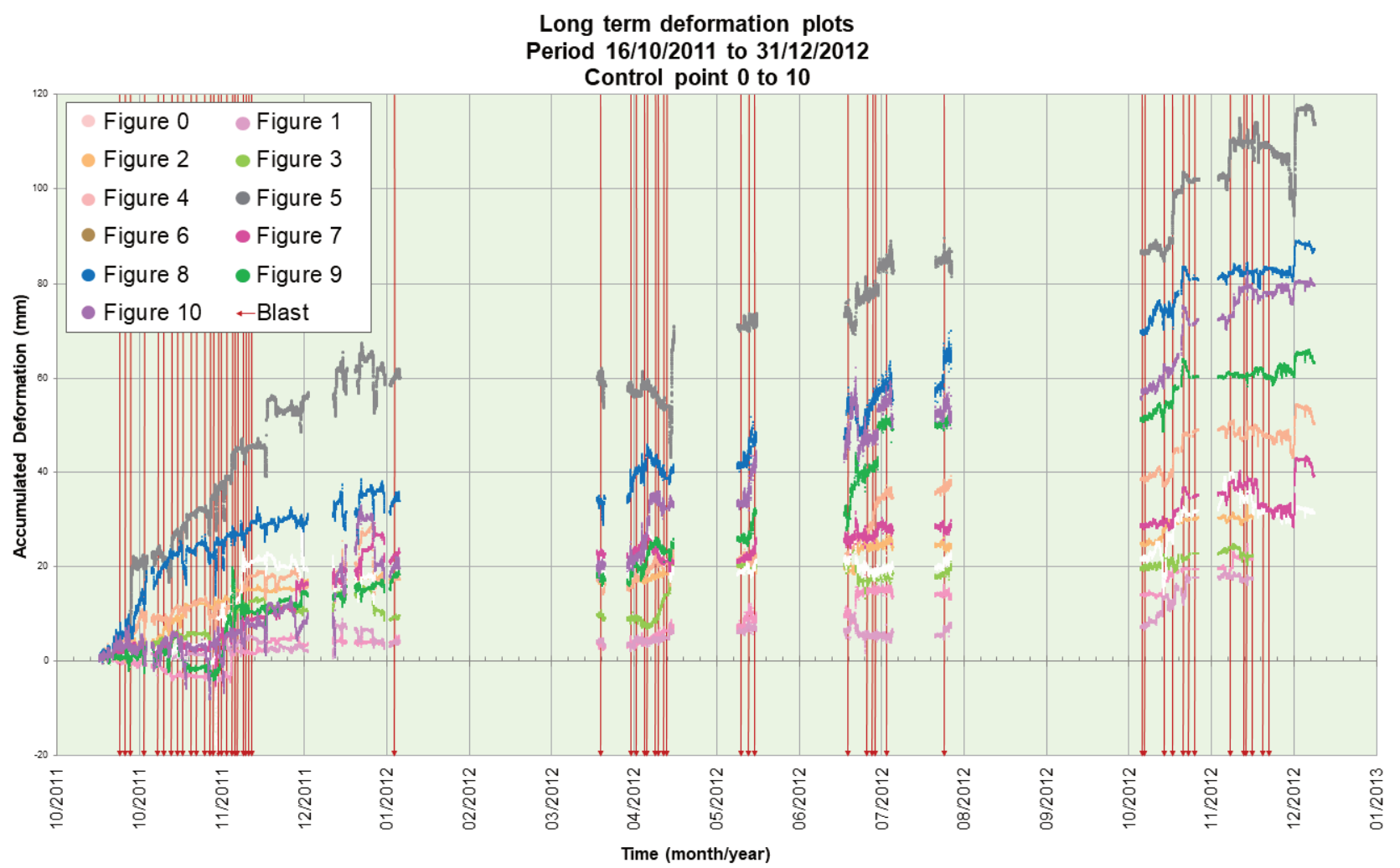

Figure 6 Selected control points for the long-term regional response to blasting analysis

The area that was directly disturbed by the blast was identified by using the deformation and coherence information from the SSR. A number of control points were located on the area, both on loose materials and on the intact rock mass, including the control points that were used for the long-term deformation analysis. Actual blast location was assumed by looking for the disturbance in the deformation plot at the stated blast 
time. Figure 7 shows an example of how the SSR coherence image was used to identify the area that was disturbed during a blast. Figure 8 shows a clear deformation response directly behind the blast (control point 5 in green).
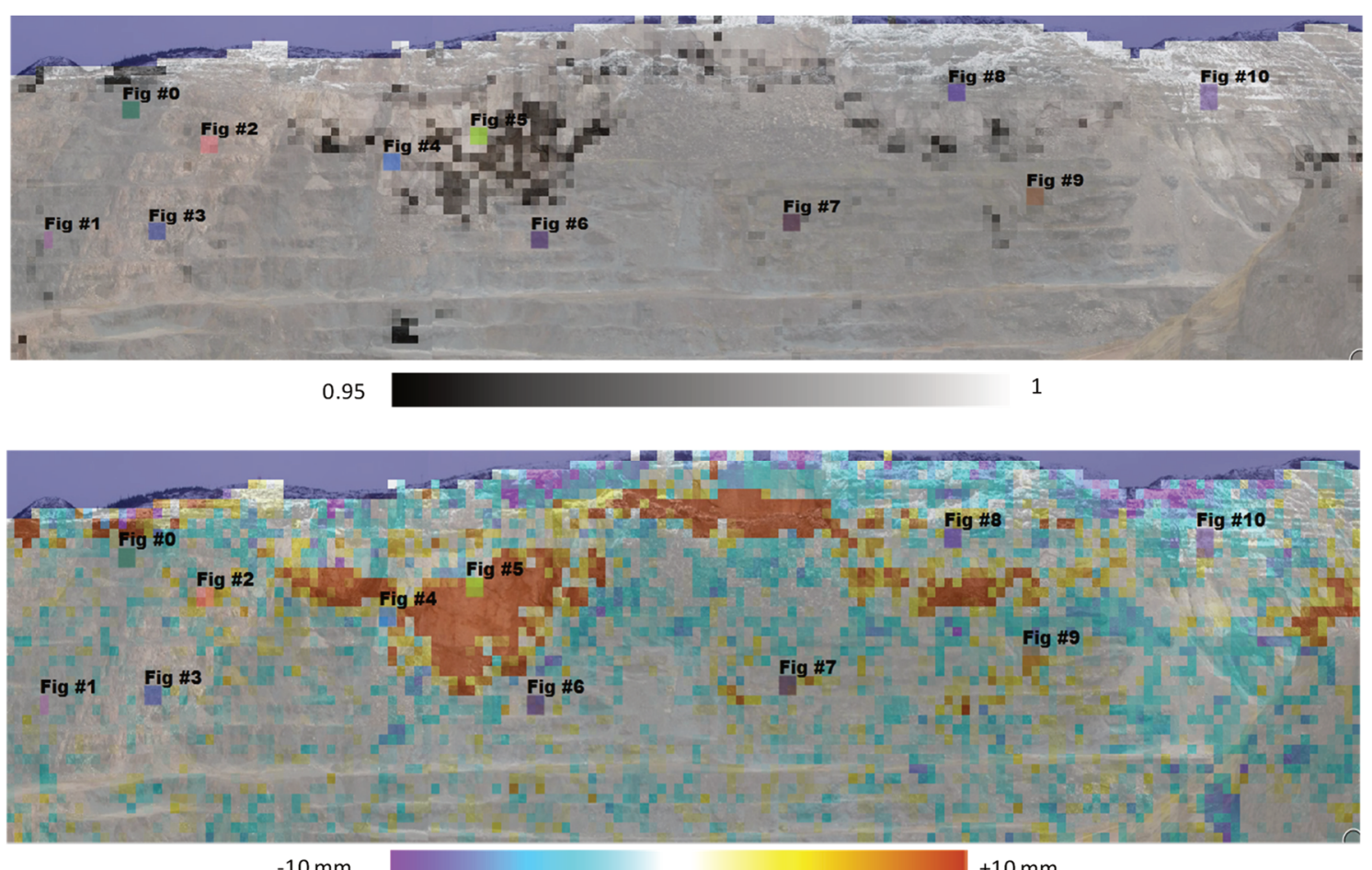

$-10 \mathrm{~mm}$ $+10 \mathrm{~mm}$

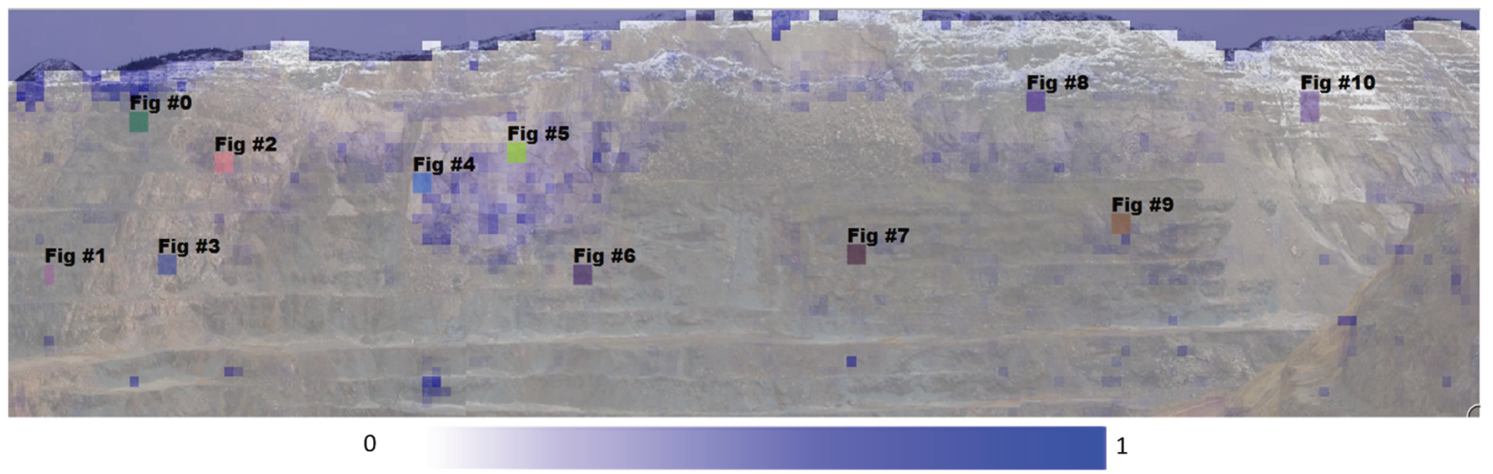

Figure 7 (a) Coherence image (at the moment of the blast); (b) Accumulated deformation (12 hours after the blast); (c) Delta coherence image (12 hours after the blast)

Deformation plots were generated for each of the control points and a velocity analysis was conducted. The deformation rates after the blast and the length of time-to-stable were then recorded. Figure 8 demonstrates a typical post-blast deformation analysis that was performed for each of the blasts. In this case, after the blast, regressive deformation processes that were observed at the control points reached rates of $18.7 \mathrm{~mm} /$ day, stabilising 17 hours after the blast.

Figure 8 shows a clearer depiction of the typical trends over a shorter time period. 


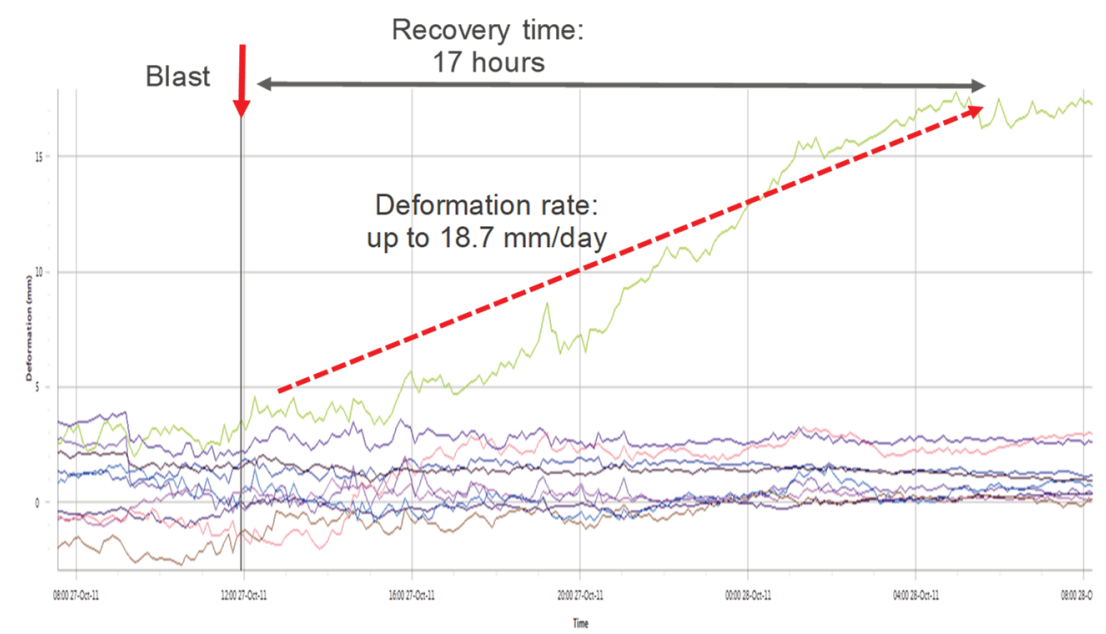

Figure 8 Accumulated deformation plots for the blast on 27/10/2011 11:57

A qualitative comparison of the results was completed in order to compare the behaviour of the different control points and to identify those areas that may show evidence of progressive damage due to blasting. Table 1 shows the damage rating chart that was applied for this analysis which assumes a degree of damage based on the time it takes for the local deformation trend to return to background rates. These time periods were applied based on the author's experience monitoring slope response to blasting in various hard rock open pit mines, they are however subjective and relative to the typical or historic response observed at the particular mine.

Table $1 \quad$ Post-blast damage rating scale

\begin{tabular}{ll}
\hline Time-to-stable & Post-blast damage rating \\
\hline$<3$ hours & Insignificant \\
3 to 6 hours & Low \\
6 to 12 hours & Moderate \\
12 to 24 hours & Significant \\
24 hours & Very significant \\
\hline
\end{tabular}

Figure 9 demonstrates a typical post-blast deformation analysis that was performed for each of the blasts. In this case, after the blast, regressive deformation processes that were observed at the control points reached rates of $3.5 \mathrm{~mm} /$ day, stabilising 12 hours after the blast. According to the damage rating system applied, the post-blast damage rating for this case is moderate.

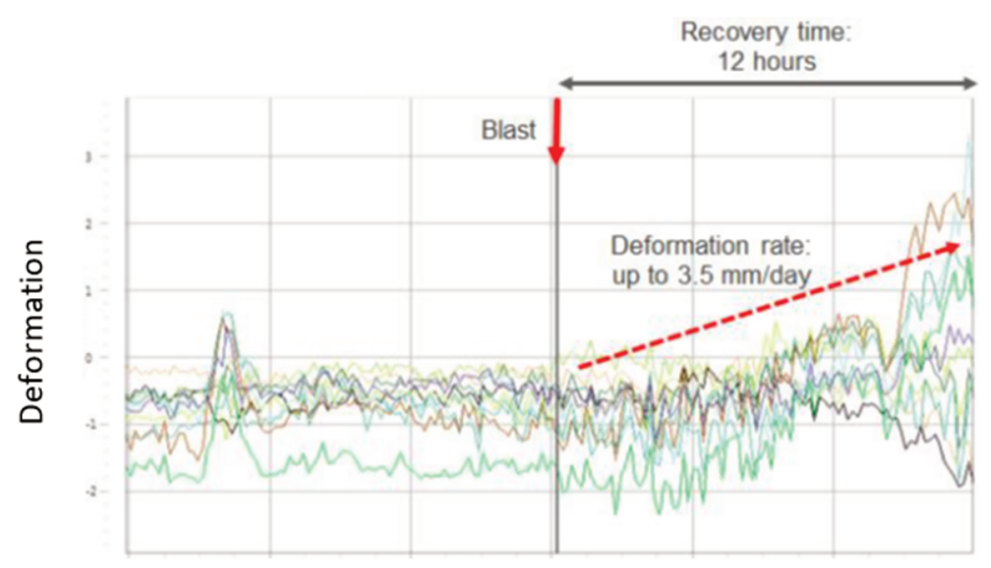

Figure 9 Post-blast deformation analysis for the blast on 26/04/2012 12:09 
Table 2 shows the resulting matrix of relative blast damage, based on the time-to-stable period observed at the control point locations after production blasts.

From Table 2, it was possible to conclude (or assume) that there was minimal evidence of either significant or progressive damage to the rock mass as a direct consequence of the blasting during the period when applying the blast damage scale as previously described. It is possible however to identify 'hot spots' where a long transient creep period was observed post-blast. This information can be used in future to assist with drill and blast design aimed to minimise any risk of significant damage which may induce local failure.

Although there are a small number of moderate (less than $5 \%$ ) and significant (less than 1\%) post-blast damage cases, as defined by the rating system, in most of the instances the post-blast damage was rated as insignificant so the risk of regional slope failure being triggered by subsequent blasting was considered to be relatively low.

\section{Table 2 Post-blast damage rating matrix}

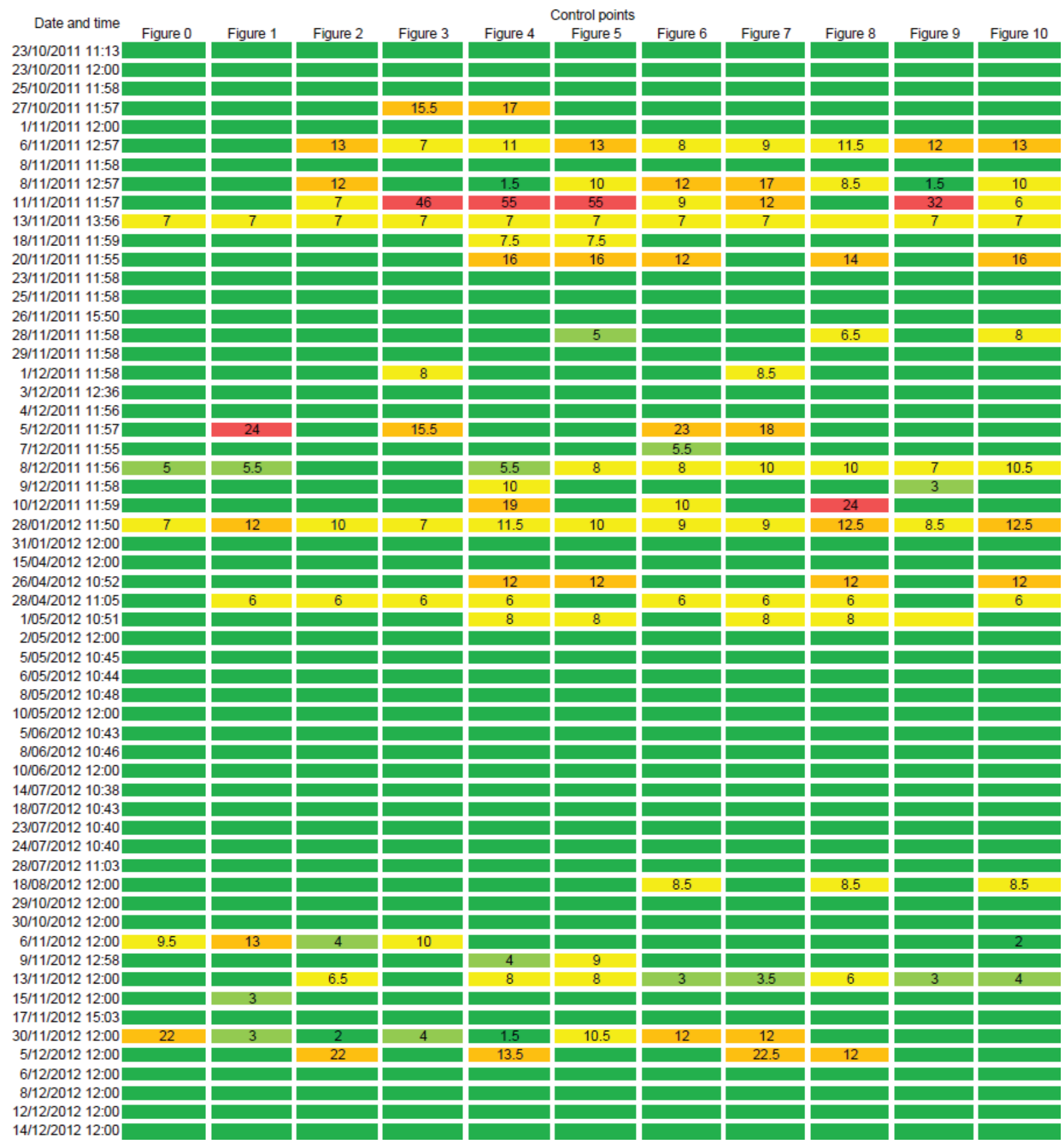




\subsection{Economic benefits assessment}

Based on the results of the long-term deformation and post-blast damage assessments, the decision was made to modify the blast design from $165.1 \mathrm{~m}$ diameter holes with a depth of $7 \mathrm{~m}$ and $300 \mathrm{~kg}$ as maximum allowable charge weights per delay to $216 \mathrm{~mm} / 311 \mathrm{~mm}$ diameter holes with a depth of $14 \mathrm{~m}$ and $550 \mathrm{~kg}$ as maximum allowable charge weights per delay. An economic benefits assessment was carried for this new blast design using two parameters: the maximum tonnage per blast, and the post-blast waiting time for resumption of mining activities. Increasing the size of blasts and reducing delays to re-enter and mine the broken stocks has a two-fold economic benefit effect of reducing mining costs and increasing production rates.

\subsubsection{Maximum tonnage per blast}

A simple assessment of the economic benefits of the new blast design recommendations was conducted. It involved a comparison of the change in the blasting design from $165.1 \mathrm{~mm}$ hole diameter with a depth of $7 \mathrm{~m}$ to $216 \mathrm{~mm}$ and $311 \mathrm{~mm}$ diameter hole with a depth of $14 \mathrm{~m}$. The same number of holes per row and the same number of rows were considered per blast. Table 3 presents the parameters used to determine the maximum tonnage per blast.

Table 3 Maximum tonnage per blast

\begin{tabular}{|c|c|c|c|}
\hline Description & $165.1 \mathrm{~mm}$ & $216 \mathrm{~mm}$ & $311 \mathrm{~mm}$ \\
\hline Bench height & 7.0 & 14.0 & 14.0 \\
\hline Density explosive (g/cc) & 1.18 & 1.18 & 1.18 \\
\hline Collar (m) & 3.0 & 3.9 & 5.6 \\
\hline Sub-drilling (m) & 0.9 & 1.2 & 1.5 \\
\hline Hole depth (m) & 7.9 & 15.2 & 15.5 \\
\hline Expected explosive column height (m) & 4.9 & 11.3 & 9.9 \\
\hline Amount of explosive per hole (kg) & 124.5 & 489.1 & 887.6 \\
\hline Average burden (m) & 4.4 & 5.55 & 7.5 \\
\hline Average spacing (m) & 4.4 & 5.55 & 7.5 \\
\hline Average area/hole $\left(\mathrm{m}^{2}\right)$ & 19 & 31 & 56 \\
\hline Average volume/hole $\left(\mathrm{m}^{3}\right)$ & 136 & 431 & 788 \\
\hline Powder factor $\left(\mathrm{kg} / \mathrm{m}^{3}\right)$ & 0.92 & 1.13 & 1.13 \\
\hline Density $\left(\mathrm{g} / \mathrm{m}^{3}\right)$ & 3.5 & 3.5 & 3.5 \\
\hline Number of holes per row (units) & 25 & 25 & 25 \\
\hline Number of rows (units) & 8 & 8 & 8 \\
\hline Number of holes per blast (units) & 200 & 200 & 200 \\
\hline Tonnage (t/hole) & 474 & 1,509 & 2,756 \\
\hline Maximum tonnage per blast $(\mathrm{t})$ & 94,864 & 301,865 & 551,250 \\
\hline
\end{tabular}

The table shows that the tonnage of blasting material increased by 3.2 to 5.8 times compared to the blast from 2011 to 2012. Thus, the new blast design measurably and quite dramatically increased the production rate and profitability of the Offload project. 


\subsubsection{Post-blast waiting time}

The second economic benefit of post-blast slope stability monitoring with SSR involved evaluation of the impact of post-blast waiting time for resumption of mining activities after each blast in terms of production costs. Without SSR, the standard process for re-entry after a production blast (end of day shift) was to commence mining at 8:00 am the following morning, after visual inspection was completed in the daylight by a geotechnical engineer. With SSR, post-blast stabilisation time can be measured following each blast. It corresponds to the time between the moment of blasting and the moment when the rate of deformation becomes constant (or zero) again. So, the resumption of mining activities in the pit after each blast can commence safely after this post-blast stabilisation time as observed and measured with the SSR.

The historic radar data collected between October 2011 and December 2012 at Paul's Peak Pit were analysed and used as a precedent for expected post-blast response in future. Figure 10 presents the standard post-blast waiting time (as per site procedure) and the actual post-blast stabilisation time following each blast. It was noted that the post-blast stabilisation time of the rock mass deformation that varied. The standard procedure post-blast waiting time was typically 20 hours.

In $9 \%$ of cases the observed post-blast stabilisation time was longer than the standard post-blast waiting time, while in $91 \%$ of cases it was significantly shorter. Thus, considering the standard post-blast waiting time to restart mining activities, the rock mass generally returned to its stable state much earlier in $90 \%$ of the cases of observed. However, for the blast ID5, the post-blast stabilisation time observed was about 34 hours longer than the standard post-blast waiting time. This suggests that the SSR can be used to both improve productivity by decreasing overly conservative delays to production and at the same time, in $9 \%$ of cases, effectively manage the risk associated with re-entry in areas where transient creep is observed over periods much longer than the standard operational practice of re-entry after visual inspection the following day.

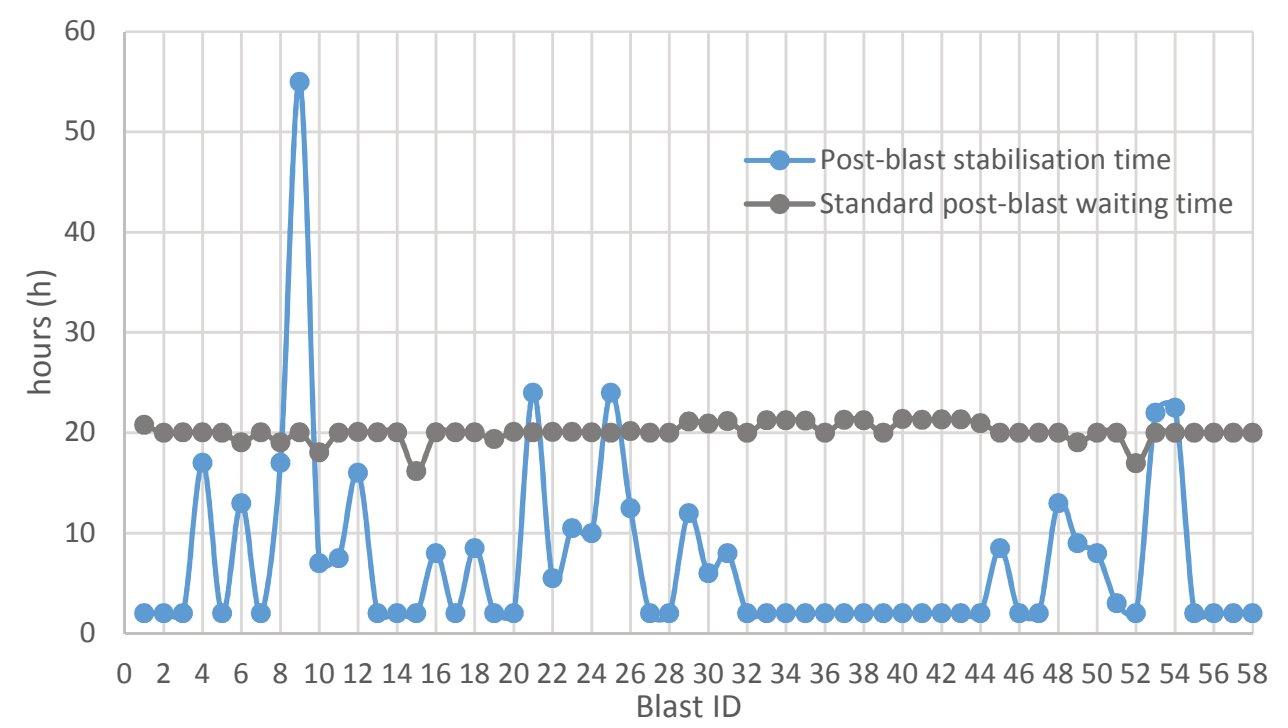

Figure 10 Curves of the standard post-blast waiting time and the post-blast stabilisation time

Figure 11 presents the cumulative curves of the post-blast stabilisation time and the standard post-blast waiting time. We can observe that a total of 1,165 hours has accumulated for the standard post-blast waiting time and 413 hours has accumulated for the post-blast stabilisation time. The difference in time that represents economic benefits using the post-blast stabilisation time versus the standard post-blast waiting time is 751 hours. Considering the post-blast waiting time costs of a shovel and six trucks assigned to the shovel, the cumulative curve of economic benefits was traced. This represents a total of $\$ 3 \mathrm{M}$ cost saving using post-blast slope stability monitoring with SSR for resumption of mining activities after each blast. Thus, the profitability of the Offload project was measurably improved with use of the SSR. 


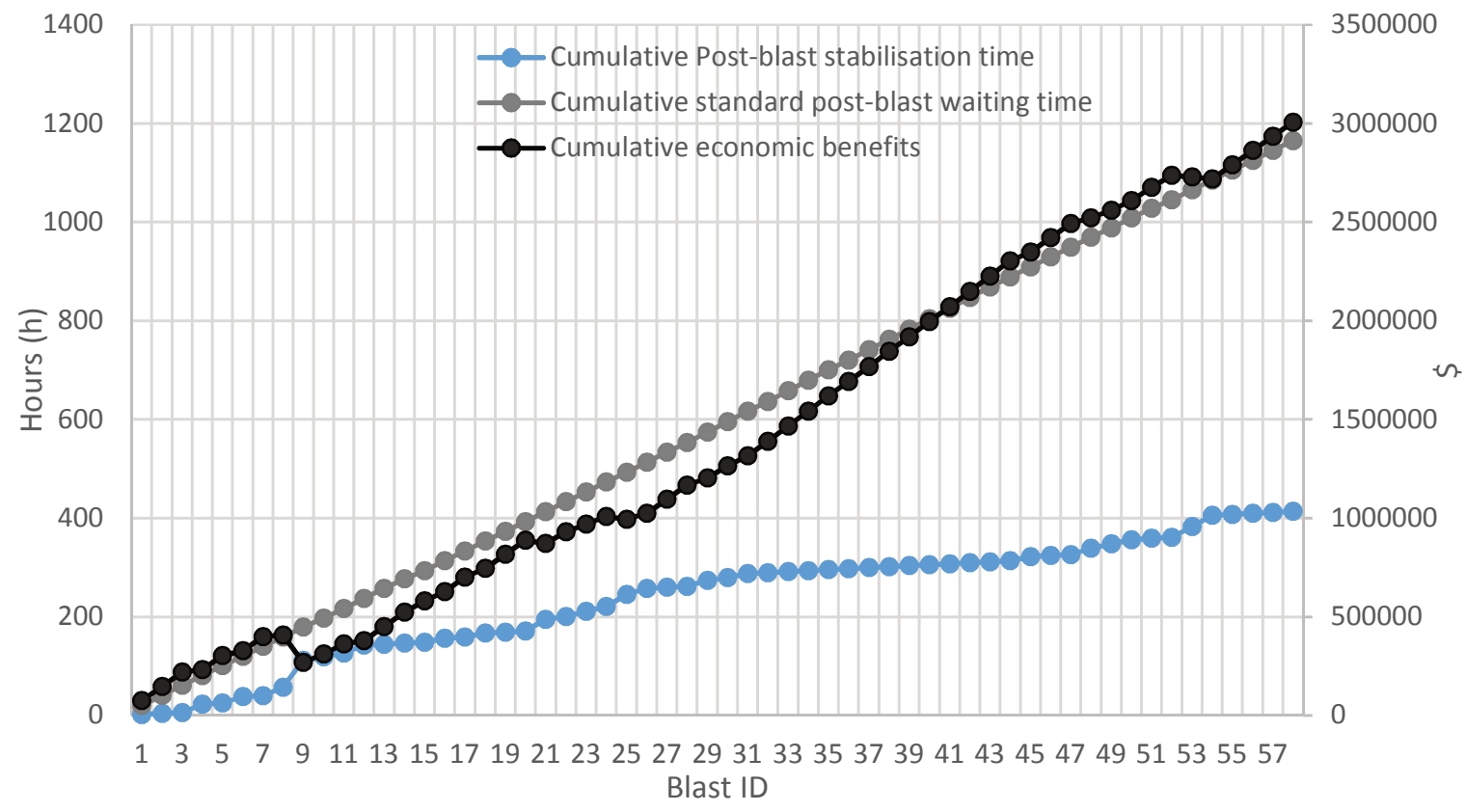

Figure 11 Cumulative curves of the standard post-blast waiting time, the post-blast stabilisation time and the economic benefits

\section{Discussion}

It is clear from the analyses conducted that there are potential safety and economic benefits associated with careful assessment of historic slope stability radar data over time following progressive production blasting in an open cut mine. It was possible from the study to conclude that there was minimal evidence of either significant or progressive damage to the rock mass as a direct consequence of the blasting during the period when applying the qualitative blast damage scale as described. It was possible to identify 'hot spots' where a long transient creep period was observed post-blast. This information was then used to determine safe re-entry times after blasting to minimise production downtime. Blasting tonnage was also maximised to further reduce costs for areas where no significant historic post-blast response had been observed.

Although there are a small number of moderate and significant post-blast damage cases, as defined by the rating system, in most of the instances the post-blast damage was rated as insignificant so the risk of regional slope failure being triggered by subsequent blasting was considered to be relatively low. It must be understood that the rating system applied was a generic qualitative scale and should be scaled relatively for a specific project depending on the rock mass strength and stiffness.

Visual inspection of the rock mass may provide additional information to assist with assessing the degree of actual blast damage. This was not possible given the assessment was completed for historic data. However, for ongoing analysis and to further optimise mining processes, the methodology as described in this paper can of course be applied with an iterative style approach with future mining. The scale and methodology described provides a basis for a qualitative assessment of the wall response to blasting but is not intended to be used for quantitative assessment.

\section{Conclusion}

The project as described in this paper represents a novel approach for post-blast assessment of slope stability using slope stability radar. The processes described can be applied to assess the impact of historic and future blasting with the aim to optimise productivity and profit while maintaining safe working conditions and minimising risk. 
It was demonstrated that an improved understanding of the expected post-blast slope response can measurably increase profitability by decreasing post-blast production downtime/delays. Maximum blasting productivity can be achieved, applying a relatively scaled maximum blast tonnage design factor in areas where no historic post-blast rock mass response has been observed with radar.

A holistic approach considering both vibration monitoring and historic post-blast slope response was applied to minimise risk and maximise profitability using slope stability radar as the key tool alongside traditional vibration monitoring methods. This approach effectively reduced the likelihood of an overly conservative blast design approach and provided the information required to justify a more aggressive and profitable mine design. Safe working conditions were maintained with ongoing monitoring with demonstrated production optimisation and measure cost savings, applying a proactive rather than reactive monitoring approach for safe re-entry after blasting.

\section{Acknowledgement}

The authors thank ArcelorMittal Mining Canada and GroundProbe for their support of this project.

\section{References}

Andrieux, P 2016, Sensibility of the South Wall of the Paul's Peak Pit to Blasting Vibrations, technical memorandum sent to ArcelorMittal Mining Canada, June.

Bourassa, PJ 1977, 'The Mount-Wright story - history and development of Mount-Wright', CIM Bulletin, April, pp. 75-82.

Hagegeorge, CG, Broemling, C \& Duthie, RH 1971, The Geology of the Carol Project Area in Southwestern Labrador, internal geological report of the Iron Ore Company.

Kabuya, JM 2019, ArcelorMittal Mining Canada, Fermont, viewed 15 October 2019, https://www.transformerlavenir.com/en/facilities/ Mercer, KG \& Stacey, TR 2008, 'A generalised time and event dependent deformation model for unsupported rock slopes', in Y Potvin, J Carter, A Dyskin \& R Jeffrey (eds), Proceedings of the First Southern Hemisphere International Rock Mechanics Symposium, Australian Centre for Geomechanics, Perth, pp. 481-492.

Noon, D 2003, 'Slope stability radar for monitoring mine walls', Mining Risk Management Conference, The Australasian Institute of Mining and Metallurgy, Melbourne, pp. 1-12. 
